\title{
Saline-Filled Cuff-Punctured Percutaneous Dilatational Tracheostomy
}

\author{
Shun-Mao Yang and Pei-Ming Huang* \\ Division of Thoracic Surgery, Department of Surgery, National Taiwan University Hospital, Taipei, Taiwan
}

Submission: February 20, 2017; Published: February 27, 2017

*Corresponding author: Pei-Ming Huang, Department of Surgery, National Taiwan University Hospital and National Taiwan, University College of Medicine, Taipei, Taiwan 7, Chung-Shan South Road, Taipei 10002, Taiwan, Tel: +886-2- 23123456, ext. 63509; Fax: +886-2- 23415736;

Email: e370089@gmail.com

\section{Abstract}

Percutaneous dilatational tracheostomy (PDT) under bronchoscopy and ultrasonography is safe and effective. Although cuff puncture is a known adverse event during PDT, a saline-filled endotracheal tube cuff might enhance ultrasound images and act as a target for endotracheal puncture. Using a novel technique, the saline-filled cuff can be identified and adjusted to the puncture location under ultrasound. Once saline is withdrawn through the puncture needle, the endotracheal tube is placed distally for detachment; the needle tip remains in the trachea for guidewire insertion. Use of dye-mixed saline, a tube exchanger during cuff puncture, and distal tube placement enables effective PDT.

Keywords: Saline-filled cuff; Percutaneous Dilatational Tracheostomy; PDT

\section{Introduction}

Percutaneous dilatational tracheostomy (PDT) is commonly performed in the intensive care unit. Numerous studies have demonstrated the safety and effectiveness of PDT under bronchoscopy and ultrasonography guidance $[1,2]$. However, a shortage of facilities and specialists required for bronchoscopy and the need for technically demanding ultrasound skills to identify both airway anatomy and position of the endotracheal tube (ETT) may hinder the use of PDT [3]. Although cuff puncture is generally recognized as an adverse event during the procedure, a saline-filled ETT cuff may enhance the ultrasound images and act as an ideal target for endotracheal puncture. We present our initial experience and serial modifications of this novel technique.

\section{Technique}

In the modified technique, the operator fills the ETT cuff with $20 \mathrm{ml}$ of colored saline mixed with $0.5 \mathrm{ml} 1 \%$ gentian violet solution for better visualization of the trachea using an ultrasound linear probe placed below the level of the cricoid cartilage in transverse scan, and gently adjusts the ETT cuff within the view of the ultrasound probe (Figure 1). A small vertical incision is made in the middle of the trachea at the level where the ultrasound probe been placed. An introducer needle is used for puncture through the incision with the trachea kept in place by the thumb and index finger (Figure 2). As the needle is advanced into the ETT cuff, colored saline is withdrawn
(Figure 3A). When more than half of the colored saline has been withdrawn, the ETT is advanced distally through the ETT exchanger and is detached from the needle while the needle tip is still in the tracheal lumen, as confirmed via air aspiration with a saline-containing syringe (Figure $3 \mathrm{~B}$ ). The guidewire is then inserted through the introducer needle (Figure 3C) and a standard PDT can be performed (Figure 3D-F). The video demonstrate the entire procedure.

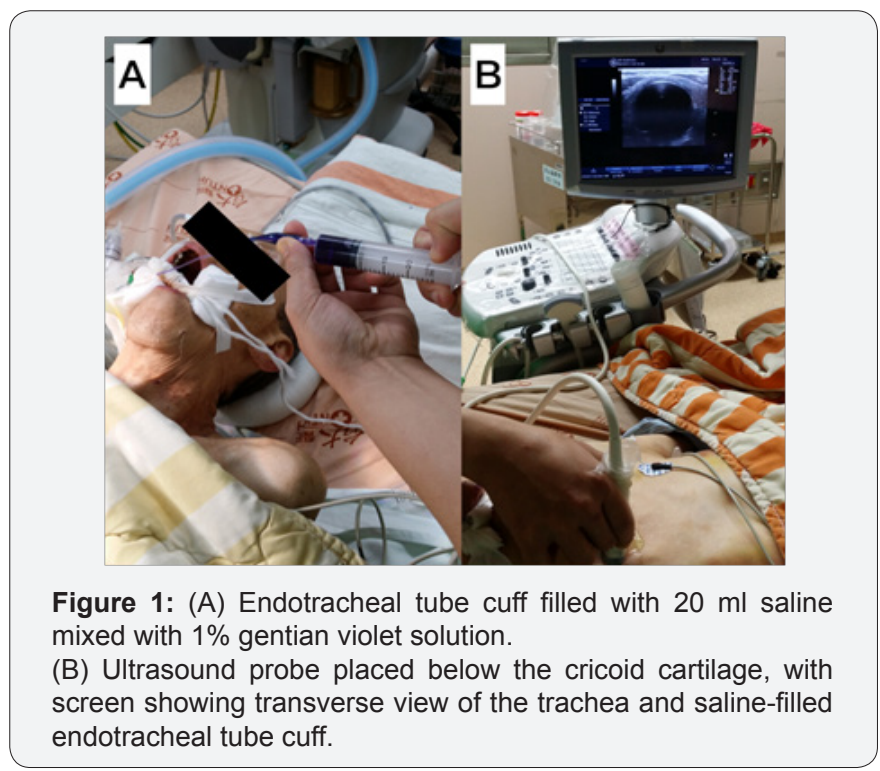




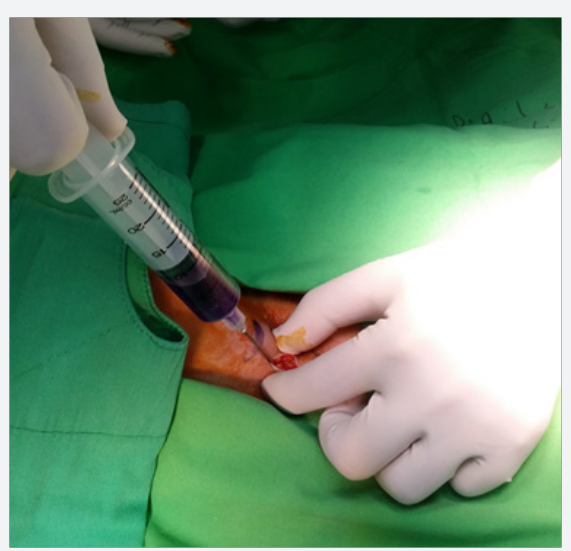

Figure 2: Colored saline was withdrawn after puncturing the endotracheal tube cuff. The trachea was fixed by the thumb and index finger during the puncture procedure.

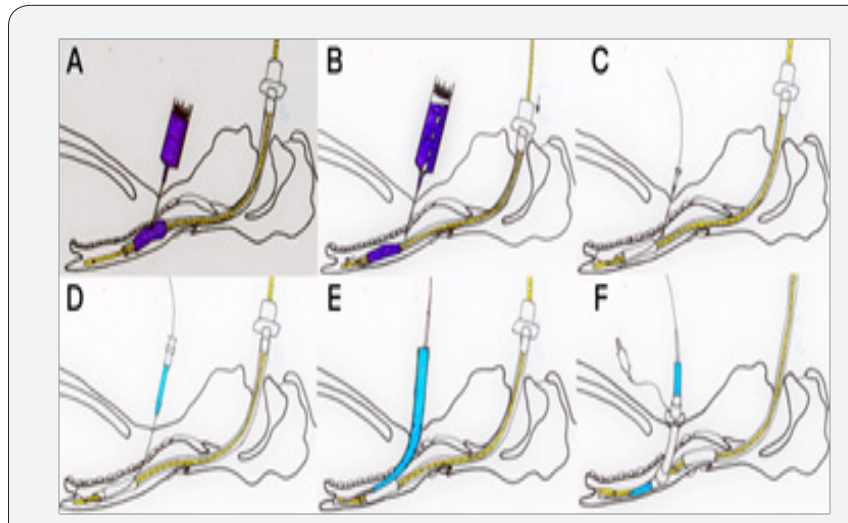

Figure 3:

(A) Puncture of saline-filled endotracheal tube cuff,

(B) Endotracheal tube distally pushed through tube exchanger to detach the needle tip,

(C) Guidewire insertion,

(D) Use of a small dilator through the guidewire,

(E) Use of a single Ciaglia Blue Rhino® dilator,

(F) A tracheostomy tube with inner dilator is used to cannulate the trachea.

\section{Comment}

A saline-filled ETT cuff has been used to confirm adequate placement of the ETT. A cadaver study [4] demonstrated that a saline-filled ETT cuff allowed novice sonographers to accurately visualize the ETT within the trachea, and a tracheal rapid ultrasound saline test has also been used to confirm correct ETT insertion depth in children [5]. In our institute, use of a salinefilled ETT cuff improved sonographic visualization of the airway anatomy and also helped to identify an adequate puncture location for percutaneous dilatational tracheostomy (PDT). However, repeated episodes of cuff puncture occurred during our initial use of PDT; we found that the superior ultrasound visualization provided by use of a saline-filled cuff was usually accompanied by unintentional cuff puncture.
Recent clinical reports described ultrasound imaging of a saline-filled cuff for accurate repositioning of the ETT during PDT; however, only a description of the images and no details related to the procedure had been reported [6]. Since the salinefilled cuff appeared as an ideal puncture target on sonography, we started our own cuff puncture PDT program using a larger amount of saline $(20 \mathrm{ml})$, which is safe for an ETT size 7.0 to 8.0 cuff, to enlarge the puncture target. After several initial cases, we found that if saline was mixed with blood or airway secretions, or if the amount of withdrawn saline was insufficient, we were less confident in our ability to determine whether the needle tip had punctured the ETT cuff; therefore, we used dye-mixed saline for subsequent cases, and were able to satisfactorily confirm accurate cuff puncture.

Real-time ultrasound-guided puncture is feasible for PDT, but is not necessary if the puncture level has been previously determined by ultrasound; moreover, it is helpful to fix the trachea with index finger and thumb during cuff puncture. After more than 30 cases, we identified a potential problem when distal ETT advancement is not accurately performed, which may result in the needle remaining in the cuff, with subsequent failure of the procedure. This may be due to kinking of the ETT in the oral cavity; therefore, we started to use a tube exchanger for effective inward placement of the ETT, which has worked well. A recent clinical study also described inward placement of the ETT during PDT without outward placement of the tube [7], thus lowering the risk of inadvertent ETT dislodgement. By using dye-mixed saline and a tube exchanger during cuff puncture, and distal placement of the ETT, the procedure can be performed more effectively and with confidence, and provides an alternative technique for PDT.

\section{Video}

This video presented step-by-step techniques of saline-filled cuff-punctured percutaneous dilatational tracheostomy.

h t t p : / / d rive.google.com / fil e / d / 0 B 9 L J c xhdMRDa3gtck9RS2xXWHM/view

\section{References}

1. Alansari M, Alotair H, Al Aseri Z, Elhoseny MA (2015) Use of ultrasound guidance to improve the safety of percutaneous dilatational tracheostomy: a literature review. Crit Care 19(1): 229. 
2. GadkareeSK, Schwartz D, Gerold K, Kim Y (2016) Use of Bronchoscopy in Percutaneous Dilational Tracheostomy. JAMA Otolaryngol Head Neck Surg 142(2): 143-149.

3. Rajajee V, Fletcher JJ, Rochlen LR, Jacobs TL (2011) Real-time ultrasound-guided percutaneous dilatational tracheostomy: a feasibility study. Crit Care15(1): R67.

4. Uya A, Spear D, Patel K, Okada P, Sheeran P, et al. (2012) Can novice sonographers accurately locate an endotracheal tube with a salinefilled cuff in a cadaver model? A pilot study. AcadEmerg Med 19(3): 361-364.
5. Tessaro MO, Salant EP, Arroyo AC, Haines LE, Dickman E (2015) Tracheal rapid ultrasound saline test (T.R.U.S.T.) for confirming correct endotracheal tube depth in children. Resuscitation 89: 8-12.

6. Anand K, Monish N, Ramprasad R, Vikas S (2016) Ultrasound imaging of saline-filled endotracheal tube cuff for accurate repositioning of tube during percutaneous dilatational tracheostomy. Intensive Care Med 42(8): 1287-1288.

7. Singh Sangwan Y, Chasse R (2016)A modified technique for percutaneous dilatational tracheostomy: A retrospective review of 60 cases. J Crit Care31(1): 144-149.

\section{Your next submission with Juniper Publishers will reach you the below assets}

- Quality Editorial service

- Swift Peer Review

- Reprints availability

- E-prints Service

- Manuscript Podcast for convenient understanding

- Global attainment for your research

- Manuscript accessibility in different formats

( Pdf, E-pub, Full Text, Audio)

- Unceasing customer service

Track the below URL for one-step submission https://juniperpublishers.com/online-submission.php 